STUDY POPULATION: This physician-scientist experience offers research opportunities in a wide variety of research disciplines, focused on clinical and translational investigations. The program offers both five-month and one-year blocks of protected research time. The five-month option is integrated into the four-year medical curriculum. The one-year option requires enrollment in an established Master of Clinical Research degree. Both options provide research experience under the mentorship of a physician-scientist. The five-month option aligns with UME competencies categorized under the six ACGME Domains of Competence. The one-year option includes coursework in research design, biostatistics, research ethics, data management, scientific communication, and proposal development within the CTSA-based education program. All students in the program attend a bimonthly journal club and seminar series starting in year one and extending through the research experience. This includes discussion of the importance of mentorship, selecting a residency, scientific writing and presentation, and personal narratives of physician-scientists and their pathways to this career. All students will be followed to determine career outcome. RESULTS/ANTICIPATED RESULTS: Between 2015 and 2018, 67 students entered the program $46 \%$ selected the year out, and $56 \%$ selected the 5 -month option. Students selecting this program constitute about $10 \%$ of the medical student population overall. We have had 17 graduates of the program to date. $55 \%$ of the cohort is women which parallels the OHSU medical student population. Long-term follow-up of at least 10 years will be needed to determine career outcomes. We assess student productivity by traditional measures of submitted abstracts, manuscripts, and presentations as well as longer term outcomes such as career orientation in medicine such as entry into a research-oriented residency and ultimately into an academic medicine or research. DISCUSSION/SIGNIFICANCE OF IMPACT: The OHSU physician-scientist experience successfully matches medical students with a diverse set of research mentors focused on the CTSA. Although institutional structures determine the variety of specific research opportunities, the integration of physician-scientist training into a CTSA-based training program expands the reach of training programs such as the TL1.

3308

\section{Training KL2 Scholars to Communicate Science to a General Audience}

Cynthia Ann Carnes ${ }^{1}$, John W. Christman ${ }^{1}$, Mark Damian Wewers ${ }^{1}$, Stuart D Hobbs ${ }^{1}$ and Rebecca Jackson, M.D. ${ }^{1}$

${ }^{1}$ The Ohio State University

OBJECTIVES/SPECIFIC AIMS: Verbal communication is a critical component for professional development and leadership. Yet, many clinical translational scientists lack the skills in communication of their scientific work in a meaningful and exciting manner that conveys the potential impact of their work on human health to the lay public, stakeholders, and to other scientists in different fields. We hypothesized that formal communication training could improve information transfer by trainees that would enhance their career development. METHODS/STUDY POPULATION: We therefore formalized a program for the KL2 scholars at the Ohio State University Center for Clinical and Translational Science that provided training from communications experts to develop a short, concise, and relevant talk about their field of research to general audiences. The program was a hybrid of workshop and individualized training. It culminated in each of the six scholars presenting public talk at the OSU STEM research dissemination and outreach space, the STEAM Factory. The scholars were administered a survey to assess their knowledge of the concepts presented in the training prior to and following the receiving the treatment, as well as their overall assessment of the experience. RESULTS/ANTICIPATED RESULTS: The poster will present the positive results of this evaluation and the impact of the training on the KL2 scholars. DISCUSSION/SIGNIFICANCE OF IMPACT: The poster explain the training as a model that other CTSA KL2 programs could adapt for their trainees.

\section{Transmitting wisdom and enhancing KL2 training through the use of exit presentations}

Michelle Lamere, MPA ${ }^{1}$, Megan Larson, David H. Ingbar, MD and Kelvin O. Lim

${ }^{1}$ University of Minnesota CTSI

OBJECTIVES/SPECIFIC AIMS: -Transmit learning and wisdom from past scholars -Predispose new scholars towards a receptive attitude Normalize struggle and failure on the road to success -Encourage a community of accomplishment and celebration -Connect the scholar METHODS/STUDY POPULATION: The exit presentations were given by NCATS funded junior faculty in the CTSI KL2 Scholars Program who had graduated. All KL2 Scholars take part in the K Scholar Multidisciplinary Seminar Series that meets weekly during the academic calendar. The departed scholars returned for the presentations the following semester. The audience was made up of KL2 who had started with a later cohort, the CTSI KL2 program is a 3-year program, and newly appointed scholars. Scholars were given 12-15 minutes to cover: 1) What was learned, 2) Accomplishments on specific aims, 3) Next steps for project and career, and 4) Recommendations for other scholars. Presentations were collected and reviewed for recurring themes. Themes were grouped and quotes were included to identify nuance. RESULTS/ ANTICIPATED RESULTS: From the 17 exit presentations, six themes were identified: 1) Don't miss the forest for the trees (x10) - "the KL2 program helps to fill in gaps scholars don't realize they have - it is about more than just the research project, trust in the process and let the program help keep you on track." 2) Diversify and keep an open mind (x7) - "focus is important but diversifying research and reorganizing priorities is ok." 3) Don't be discouraged by failure (x6) -" perseverance is key, all success comes on the heels of many failures." 4) Importance of building network inside and outside of Scholar program (x6) - "importance of exploring and establishing collaborations" 5) Learn to say no and yes (x5) - "protect your time but be open to opportunities" 6) Seek advice and criticism but don't follow blindly (x4) DISCUSSION/SIGNIFICANCE OF IMPACT: The use of exit presentations for graduating KL2 Scholars is a useful tool in transmitting wisdom and enhancing subsequent KL2 cohorts. The Scholar's experience and trajectory, share personal insights and recommendations to help other Scholars get the most out of their KL2 experience, give the community a chance to celebrate the Scholar's accomplishments, and provide the Scholar with a sense of closure in their KL2 journey. Within the exit presentations, six common themes emerged relating to best practices on making good use of resources and guidance, and learning to interact and navigate within networks and responsibilities in a mature way. Scholars in the audience benefit from hearing the insights and advice from their predecessors. The identification of themes helps the program to understand where it adds value. 